\title{
0 processo de desenvolvimento profissional visto pelos professores mentores
}

\author{
Maria do Céu Roldão* \\ Teresa Leite ${ }^{* * *}$
}

\section{Resumo}

Neste artigo apresentam-se e discutem-se os resultados da análise de 74 reflexões realizadas pelos mentores relativamente à oficina de formação em que participaram. Os resultados permitem concluir que os professores mentores consideraram que a formação contribuiu para o seu desenvolvimento profissional e, através deles, para o desenvolvimento profissional dos professores em periodo probatório que supervisionavam. No entanto, os professores mentores referem-se consideravelmente menos ao contributo da formação para o desenvolvimento organizacional das escolas e preveem escassas repercussões a esse nível. Quanto ao processo de formação, consideram-no útil e de qualidade, valorizando essencialmente os documentos trabalhados nas sessões e as estratégias utilizadas.

Palavras-chave: Formação de professores. Desenvolvimento profissional. Mentoria. Período probatório.

\section{The professional development process as perceived by teachers' mentors \\ Abstract}

In this paper we present and discuss the results of 74 reflections made by mentors regarding the training workshops in which they took part. The results show that teachers mentors consider that the training contributed to their professional development and, through them, to the professional development of teachers who they supervised during the probation period. However teachers mentors refer considerably less to the contribution of training towards the organizational development of schools and foresee little impact at this level. As

\footnotetext{
* Pós-Doutorado em Teoria e Desenvolvimento Curricular, Universidade Católica Portuguesa; Professora e Investigadora na Faculdade de Educação e Psicologia da Universidade Católica Portuguesa. E-mail: mroldao@ucpcrp.pt

** Pós-Doutorado em Ciências da Educação, Escola Superior de Educação de Lisboa; Professora e Investigadora na Escola Superior de Educação do Instituto Politécnico de Lisboa. Email: teresal@eselx.ipl.pt
} 
for the training process, they consider it useful and of quality, valuing mainly the documents worked on during sessions and the strategies used.

Keywords: Teachers'education. Professional development. Mentorship.

Probation period.

\section{El proceso de desarrrollo profesional analizado por los profesores mentores Resumen}

En este artículo se presentan los resultados del análisis realizado sobre 74 reflexiones hechas por los mentores sobre el taller de formación en el que participaron. Los resultados concluyen que los profesores mentores consideraron que la formación contribuyó para su desarrollo profesional, y a través de ello, para el desarrollo profesional de los profesores en periodo probatorio que supervisaban. Los profesores mentores se refieren poco a la contribución de la formación para el desarrollo organizacional de las escuelas y consideran que habrá escasa repercusión a ese nivel. En cuanto al proceso de formación, lo consideran útil y de calidad, valorando esencialmente los documentos elaborados en las sesiones y las estrategias utilizadas.

Palabras clave: Formación docente. Desarrollo profesional. Mentoría. Período probatorio

\section{Enquadramento}

0 enquadramento e apoio ao processo de acompanhamento aos professores em período probatório (ano letivo 2009-2010) tiveram como eixo-chave uma oficina de formação destinada aos professores mentores que, junto deles, exerciam funções de supervisão, num quadro de dificuldade conjuntural inerente à novidade do processo, às circunstâncias em que foi implementado, e ainda a algumas disfunções de cariz administrativo que atrás se referenciaram 1 .

Esta oficina de formação foi concebida como o veículo que se configurou mais adequado para intervir no processo, uma vez que o acompanhamento direto das 81 escolas e 85 professores em periodo probatório (PPP) se apresentava como impossivel. Optou-se assim por uma estratégia formativa paralela às fases de desenvolvimento profissional inseridas no apoio ao ano probatório, dirigida aos professores mentores (PM) que indiretamente se tornavam seus desmultiplicadores junto dos PPP. Para além disso, os PM podiam também vir a ser agentes de algum envolvimento das escolas e seus órgãos intermédios no processo em que desempenhavam o papel de charneira.

1 Vd Roldão, Reis e Costa. Da incoerência burocrática à eficácia de um dispositivo de Supervisão/Formação artigo introdutório deste dossiê temático. 
0 processo formativo acompanhou, portanto, as fases do desenvolvimento previsto para o ano probatório: diagnóstico/análise de necessidades, acompanhamento e monitorização da conceção e planejamento estratégico da ação docente, da realização das aulas e sua avaliação, dos resultados de aprendizagem, e da reorientação quando necessária das estratégias e materiais. Como referido antes ${ }^{2}$, em cada sessão, orientada por questões nucleares relativas a estas diferentes fases do processo de APP, debatiam-se os problemas encontrados pelos PM na sua tarefa de supervisionar os colegas, analisavam-se os problemas surgidos e fornecia-se apoio teórico e bibliográfico para trabalhar e aprofundar as dimensões em foco em cada fase. Entre as sessões, eram pedidas tarefas a realizar pelos PM com os seus PPP, de cujos resultados era posteriormente dado feedback.

No final, foi pedido aos PM que elaborassem uma reflexão crítica sobre o processo e sobre os seus efeitos, numa perspetiva autoanalítica. A reflexão sobre a prática implica uma forma especifica de pensamento que, como já afirmava Dewey (1933, apud ALARCÃO; TAVARES, 2010), exige um distanciamento do objeto de análise e a capacidade de o questionar, problematizar e procurar alternativas. Com Schon (1983, 1987), este conceito populariza-se no campo da formação em geral e da formação de professores em particular, distinguindo-se diferentes fases e niveis reflexivos (reflexão na ação, reflexão sobre a ação e sobre a reflexão na ação), os quais vêm pôr em relevo o papel da reflexividade na construção do conhecimento profissional.

Como refere Alarcão (2000, p. 16), a abordagem do professor como profissional reflexivo "fez eco da tomada de consciência sobre a imprevisibilidade dos contextos de atuação profissional e trouxe à luz do dia a riqueza da epistemologia da prática explicada por Schon (1983; 1987)". A reflexividade constitui-se pois como o elemento caraterizador central de uma outra forma de estar no ensino, favorecendo a produção de um saber próprio da profissão, por oposição à ideia, geralmente aceite, de que o saber do professor se reduz ao domínio dos conteúdos e técnicas de ensino (ROLDÃO, 2001). De natureza socioconstrutivista, esta abordagem implica uma interação constante entre ação e pensamento, que estará na base de um conhecimento profissional contextualizado e sistematizado. 0 conhecimento profissional não se reduz, portanto, ao saber fazer, mas implica o saber fazer, saber como fazer, e saber porque se faz, isto é, a um conhecimento produzido ou mobilizado pelos atores na prática de ensinar (ROLDÃO, 2007).

Esta noção de conhecimento profissional docente implica a criação de processos formativos numa lógica de construção na ação, "[...] construindo dispositivos que possibilitem o uso, a construção e a reconstrução de saber pelos e com os professores, nos contextos de ação educativa que desenvolvem, teorizando-a e fazendo dela o eixo da produção de saber" (ROLDÃO, 2005, p. 297).

2 Vd Leite, T. - 0 programa de formação dos mentores: conceção e planejamento - artigo inserido neste dossiê temático 
Como orientação geral para a elaboração das reflexões, sugeriu-se aos professores mentores que redigissem uma breve caracterização da situação de partida (incluindo o tipo de escola e o perfil do PPP e PM: área disciplinar, anos de serviço como professor e anos de serviço na atual escola) e que o documento fosse elaborado de modo a responder às seguintes questões:

- Que importância assumiu a formação para o processo de supervisão?

- Quais as aprendizagens mais significativas para o desempenho da função de mentor?

- Que aspetos contribuíram para essas aprendizagens?

- Como foram mobilizadas/usadas nas ações de supervisão? Com que impacto no desenvolvimento profissional dos professores em periodo probatório (PPP)?

- Que sugestões para processos de apoio a tarefas de supervisão desta natureza a realizar no futuro?

Foram recebidos 74 documentos que foram sujeitos a uma análise de conteúdo categorial, com campos de análise constituidos previamente, criando-se depois categorias e subcategorias a partir do conteúdo em análise (ESTEVES, 2005).

Assim, consideraram-se como campos de análise:

- Contribuições da formação para o desenvolvimento profissional dos professores mentores;

- Contribuições da formação para o desenvolvimento profissional dos professores em período probatório;

- Contribuições da formação para o desenvolvimento organizacional das escolas;

- Qualidade e utilidade globais do processo formativo.

Em termos globais, da análise realizada, é possivel destacar que os professores mentores salientam a contribuição da formação para o seu desenvolvimento profissional, referindo quer aspetos de natureza conceptual, quer aspetos de natureza operativa, com pesos variáveis, que adiante se explicitarão. Consideram também que a sua formação teve reflexos significativos no desenvolvimento profissional dos professores em período probatório que acompanhavam. No entanto, a análise das reflexões mostra que os professores mentores se referem consideravelmente menos ao contributo da formação para o desenvolvimento organizacional das escolas, surgindo referências a limitações a esse nivel. Quanto ao processo formativo propriamente dito, os professores mentores, nas reflexões, explicitam aspetos positivos, mas também aspetos negativos que adiante se analisam em mais detalhe, sendo as dimensões negativas associadas à organização e temporalidade da formação, que muitos desejariam anterior ao início do processo.

Apresentamos, em seguida, uma abordagem mais detalhada destes resultados, organizada de acordo com os quatro campos atrás mencionados. 


\section{Contribuição da formação para o desenvolvimento profissional dos mentores}

Nos resultados relativos à contribuição da formação para o desenvolvimento profissional dos mentores, distinguimos a dimensão conceitual e a dimensão operativa, como o Quadro 1 mostra.

Quadro 1 - Contribuição da formação para o desenvolvimento profissional dos mentores.

\begin{tabular}{|c|c|c|c|}
\hline Categorias & Subcategorias & $\begin{array}{l}\mathrm{T} \\
\mathrm{SC} \\
\end{array}$ & $\begin{array}{l}\mathrm{T} \\
\text { Cat }\end{array}$ \\
\hline \multirow{5}{*}{$\begin{array}{l}\text { Dimensão } \\
\text { conceitual }\end{array}$} & Análise da prática & 14 & \multirow[b]{5}{*}{88} \\
\hline & Valorização do trabalho cooperativo & 24 & \\
\hline & Desenvolvimento de competências de supervisão & 30 & \\
\hline & Experimentação de um novo papel & 9 & \\
\hline & Segurança como supervisor & 11 & \\
\hline \multirow{10}{*}{$\begin{array}{l}\text { Dimensão } \\
\text { operativa }\end{array}$} & Organização do ciclo supervisivo & 16 & \multirow[b]{10}{*}{91} \\
\hline & Técnicas e instrumentos para observação de aulas & 19 & \\
\hline & Modos de fornecer feedback formativo & 10 & \\
\hline & Elaboração conjunta de grelhas de avaliação dos & 5 & \\
\hline & Planejamento de sequências didáticas & 15 & \\
\hline & Operacionalização das dimensões do ato de ensinar & 16 & \\
\hline & Clarificação da definição de critérios de avaliação e & 3 & \\
\hline & Melhoria das aprendizagens dos alunos & 3 & \\
\hline & Avaliação com efeitos formadores & 2 & \\
\hline & Superação das diferenças de formação de base & 2 & \\
\hline
\end{tabular}

Fonte: As autoras (2012).

Na dimensão conceitual, 30 professores mentores salientam o desenvolvimento de competências de supervisão, particularmente a partir da análise de erros e preconceções. Uma das mentoras escreve, por exemplo:

"Olhando para o ponto de partida e para o de chegada, considero que os resultados obtidos são globalmente muito positivos, pois, neste momento, não cometeria os mesmos erros, seria capaz de definir uma estratégia mais eficaz para a abordagem do processo de supervisão e apoiar melhor a PPP" (M4 EV).

Outro mentor refere: 
"A participação em todas as sessões de formação realizadas contribui para ascender a outro patamar de desenvolvimento e aprofundamento do meu saber profissional e de crescimento na qualidade da minha prática docente, pois, até então, e apesar de ao longo da carreira ter sido solicitado várias vezes para o acompanhamento e supervisão de estágios pedagógicos, nunca direcionei a minha ação para essa área do meu desenvolvimento profissional. Contudo, e em virtude de no passado ano letivo, por força da nova legislação de avaliação do desempenho dos professores, ter sido quase obrigado a realizar a função de supervisão e avaliação de professores, considerei que a formação que acompanhei me poderia fornecer mais instrumentos que contribuiriam para esta lacuna do meu desenvolvimento profissional" (M6 FA).

A valorização do trabalho colaborativo e o confronto analítico e reconstrutivo de perspetivas e experiências que a formação estimulou são também salientadas por 24 mentores. De algum modo, os professores mentores remetem-nos aqui para a ideia de comunidades profissionais de aprendizagem, entendidas como grupos de profissionais que partilham preocupações e aprofundam os seus conhecimentos e capacidades através de uma interação continuada (PUTNAM; BORKO, 2000), questionando a sua prática de forma reflexiva e colaborativa (STOLL et al., 2006). Para estes autores, as comunidades profissionais de aprendizagem implicam a partilha de valores e perspetivas, a responsabilidade coletiva, o diálogo reflexivo sobre a ação, a colaboração e a promoção da aprendizagem individual e coletiva, contrariando o isolacionismo e solidão tradicionais na profissão docente. 0 foco deste conceito é, por isso, a própria noção de comunidade, equacionando-se o desenvolvimento profissional enquanto produto de uma aprendizagem colegial (COCHRAN-SMITH; LYTLE, 1999).

Nesse contexto, também a noção de supervisão ganhou uma nova abrangência e novos contornos. De uma definição essencialmente baseada na interação entre supervisor e supervisionado ("o processo em que um professor, em princípio mais experiente e mais informado, orienta um outro professor ou candidato a professor no seu desenvolvimento humano e profissional" (ALARCÃO; TAVARES, 2010, p. 18), a supervisão passa a ser equacionada no contexto da escola, que se torna ela própria uma instituição aprendente (ALARCÃO, 2000), favorecendo a "dinamização e acompanhamento do desenvolvimento qualitativo da organização escola e dos que nela realizam o seu trabalho de estudar, ensinar ou apoiar a função educativa, através de aprendizagens individuais e coletivas, incluindo as dos novos agentes" (ALARCÃO; TAVARES, 2010, p. 154).

0 excerto seguinte ilustra as afirmações dos professores em relação à importância que para eles teve a interação com os colegas e o envolvimento num projeto coletivo: 
"O facto de termos trabalhado bastante em grupo e de nos ter sido proporcionada a troca de experiências e o termos vivenciado as diferentes realidades dos colegas que frequentaram a Ação de Formação, também nos facilitou a aquisição das aprendizagens e abriu-nos outros horizontes no modo como proceder com os Professores em Periodo Probatório. Deste modo, fomos alterando o nosso procedimento em função das aprendizagens que iam sendo adquiridas, principalmente no tocante à observação das aulas" (M1 AV).

0 processo formativo permitiu ainda, segundo alguns dos mentores, a análise da prática. Nalgumas das reflexões é mesmo usada a expressão "a centralidade da prática" no processo de supervisão; noutras, é salientado o incentivo e a oportunidade de questionamento sobre os saberes práticos. A reflexão sobre a prática, como afirmámos antes, pode constituir o verdadeiro motor da integração teoria-prática, constituindo-se como base do conhecimento específico da ação docente, se não for entendida apenas como descrição e constatação da ação, o que inviabiliza a produção de conhecimento sobre a ação em causa. Para que a reflexão implique uma construção de conhecimento sustentado, é necessário que se oriente para o questionamento, a formulação de hipóteses explicativas, a produção de interpretações que possam ser verificadas na ação. 0 saber profissional docente é "intrinsecamente teorizador, compósito e interpretativo" ROLDÃO (2007, apud ROLDÃO, 2011, p. 247), integrando saberes formais e saber experiencial e torna-se saber profissional quando o professor os recria num processo mobilizador e transformador, desenvolvendo uma ação especializada para promover intencionalmente a aprendizagem de alguma coisa por outros (ROLDÃO, 2005, 2008, 2009). Nesse sentido, "aprende-se e exerce-se na prática, mas numa prática informada, alimentada por velho e novo conhecimento formal, investigada e discutida com os pares e os supervisores ou, desejavelmente, tudo isto numa prática coletiva de mútua supervisão e construção de saberes interpares" Roldão (2007, apud ROLDÃO, 2011, p. 248).

A este propósito, os mentores explicitam, por exemplo:

"De assinalar que a reflexão sobre a prática pedagógica da PPP conduziu à reflexão sobre a minha própria prática e, por isso, ao meu desenvolvimento profissional" (M3 FA).

"Ao que ficou exposto devo acrescentar que, enquanto esta experiência decorreu, pude refletir muito mais sobre a minha própria prática letiva e penso ter conseguido acionar os mecanismos de supervisão autorregulada indispensáveis à construção do meu desenvolvimento profissional" (M2 EV).

Esta tomada de consciência da necessidade de analisar a sua própria ação pedagógica pode abrir novos caminhos para a reconstrução do conhecimento profissional. Com efeito, uma visão meramente praticista da ação de ensinar não constitui contributo suficiente para o desenvolvimento profissional, se queremos encarar o professor como 
profissional autónomo. "Profissionalizar a docência implica que os docentes abandonem o estatuto corrente de práticos, muito instalado no senso comum, em favor do papel de agentes de uma prática, mas teorizadores dessa prática, mediante a produção, validação e circulação do seu conhecimento específico" (ROLDÃO, 2010b, p. 39).

É nesse sentido que interpretamos as reflexões de alguns mentores sobre as aprendizagens realizadas não apenas sobre supervisão, mas também sobre o ensino e das quais apresentamos um exemplo ilustrativo:

"Aprendi que a definição explícita de um propósito e que a
clarificação de uma orientação estratégica é deveras funda-
mental para que a aprendizagem aconteça e que depende mui-
to do trabalho colaborativo para que seja possivel enriquecer
a estratégia de ensino de modo a que esta seja concebida de
forma detalhada, prevendo técnicas e procedimentos a uti-
lizar, sequências de atividades estrategicamente organizadas
e formas de avaliação pertinentes" (M8 EV).

Eventualmente decorrente dos aspetos anteriormente explicitados, a formação parece ter fornecido aos mentores a segurança necessária ao desempenho do papel de supervisores, como 11 deles referem. Um dos mentores escreve:

"Deste modo, foi extremamente importante esta ação de formação como elo de articulação entre o Ensino Superior e as Escolas Básicas e Secundárias, num trabalho de colaboração e acompanhamento, sem o qual os PM (e consequentemente os PPP) se sentiriam "perdidos", pois tinham como único referente uma legislação sobre o Período Probatório" (M7 AV).

A análise efetuada mostra uma óbvia coerência entre o que os aspetos que os mentores salientam na dimensão conceptual e os aspetos que salientam na dimensão operativa, uma vez que estes últimos constituem formas de operacionalização dos primeiros. Assim, os mentores salientam a aquisição de técnicas e instrumentos para observação de aulas e as aprendizagens sobre o desenvolvimento do ciclo supervisivo e sobre a forma de fornecer feedback formativo aos professores que acompanhavam, aspetos que deram origem às competências supervisivas anteriormente mencionadas e à consequente segurança no desempenho do seu papel como mentores.

Se "a natureza questionadora, analítica, interpretativa, teorizadora e reflexiva do trabalho supervisivo, assente num acompanhamento e discussão permanente do processo e da ação e seus resultados, parece ser um alicerce para a construção do conhecimento profissional" dos professores supervisionados (ALARCÃO; ROLDÃO, 2008, p. 54), parece também ter contribuído para o desenvolvimento profissional dos próprios 
supervisores. As novas tendências no campo da supervisão apontam, como afirmámos antes, para processos de supervisão interpares em contextos colaborativos, assumindo a escola como espaço privilegiado do desenvolvimento profissional, como comunidade aprendente e reflexiva. Mas apontam ainda para processos de autosupervisão, de natureza intrapessoal e centrados nas necessidades formativas autopercepcionadas pela análise da prática. Trata-se de um processo de autoformação continuada que favorece mudanças de posição face ao conhecimento e contribui para a construção de uma identidade profissional sólida e sustentada (ALARCÃO; ROLDÃO, 2008).

Nessa perspetiva, parece possivel afirmar que os professores mentores, para além de aprenderem a apoiar e regular o processo formativo dos professores em periodo probatório (ALARCÃO; ROLDÃO, 2008); desenvolveram também processos de autoapoio e autorregulação que Ihes permitiram progressivamente melhorar a sua prática como supervisores.

De entre as competências de supervisão recém-adquiridas, os mentores salientam a capacidade de fornecer feedback. Uma das mentoras escreve, por exemplo:"Foi útil e pertinente a tónica colocada pelos formadores na recolha de evidências por parte do PM de forma a tirar conclusões e a proporcionar feedback ao PPP, estabelecendo com este, metas de desenvolvimento. Considerando a importância do feedback, posso afirmar que a tipologia de feedback coconstrutivo e com exemplos produzidos em contexto de supervisão me ajudaram a, progressivamente, melhorar esta prática" (M2 EV).

Contrariamente à posição muito dominante nas interações verbais no início da formação, afirmando a menor importância que os formandos atribuiam à dimensão teórica e o interesse em satisfazer sobretudo as questões práticas que enfrentavam, verifica-se um uso muito direto de apoios teóricos trabalhados nas sessões, como, na citação anterior, a referência ao artigo de Alarcão, Leitão e Roldão (2009) sobre o feedback coconstrutivo.

0 feedback coconstrutivo constitui-se como um orientador da ação e do pensamento, desenvolvendo-se de modo interativo e dialógico através do questionamento e da reflexão conjuntas, de forma a contribuir para a compreensão do que se faz e do que se observa (ALARCÃO; LEITÃO; ROLDÃO, 2009).Com base em dois estudos realizados a partir de narrativas analiticas e reflexivas, os autores analisaram os tipos de feedback providenciado pelos supervisores e apresentam uma tipologia de feedback que emergiu no primeiro estudo e foi profundada, explicitada e utilizada como modelo de análise no segundo e que engloba: i) o questionamento como pedido de esclarecimento; ii) o questionamento crítico ou estimulador; iii) o apoio e encorajamento; iv) a recomendação; v) a síntese e balanço; v) o esclarecimento concetual, teórico e metodológico. Os resultados destes dois estudos confirmaram a importância do feedbackdialógico e contextualizado "como estratégia potenciadora do desenvolvimento profissional e da emergência da autossupervisão, 
expressões da construção da autonomia e emancipação profissional que, de resto, deve ser um dos principais objetivos da supervisão" (ALARCÃO; LEITÃO; ROLDÃO, 2009, p. 25).

Os mentores dão ainda relevo à operacionalização das dimensões do ato de ensinar e ao planejamento de sequências didáticas, que contribuíram para a análise da prática profissional. Como vimos antes, o conhecimento profissional necessário para fazer aprender alguma coisa a alguém é compósito e integrador, mas a sua operacionalização pode ser analisada enquanto ato profissional, sendo possivel discernir quatro grandes dimensões: i) conceção e planejamento; ii) realização; iii) avaliação; iv) reorientação. A supervisão (como a avaliação de desempenho) incide sobre estas quatro dimensões, cada uma delas decomponivel, por sua vez, num encadeado sequencial de operações e ações para as quais é necessário mobilizar conhecimento profissional: conhecimento curricular, pedagógico, científico e didático e também conhecimento do aluno e do contexto (ROLDÃO, 2010a).

Sobre esta questão, uma das mentoras escreve, novamente direcionando uma referência expressa para os recursos teóricos a que acedera e sua utilidade no aprofundamento da prática:

Foi também bastante significativa para o desempenho da função de mentora, a aprendizagem no domínio do planejamento da ação de ensinar. As atividades práticas desenvolvidas na sessão de formação destinada a esta temática, nomeadamente, a análise de diferentes tipos de planificações simuladas, e a leitura de excertos de Estratégias de Ensino: o saber e o agir do professor, de Maria do Céu Roldão, permitiram uma atualização/clarificação do conceito de planejamento (...)" (M3FA).

Como o excerto mostra, a análise da prática permitiu ainda aos professores mentores a reflexão sobre o processo de ensino e as formas de fazer aprender. 0 ato de ensinar exige um planejamento que não esgota na definição de uma forma de abordar determinado conteúdo. Exige uma a definição de uma linha orientadora que seja estratégica para o conjunto de ações a desenvolver visando um dado objetivo e que seja contextualizada a uma determinada situação. As decisões mais concretas e instrumentais, relativas a técnicas de ensino, inserem-se depois nessa conceção estratégica geral, sem a qual correm o risco de constituir formas de execução simplistas e mais ou menos ineficazes (LEITE, 2010). Esta conceção da ação de ensinar implica que se equacione o professor como um profissional com autonomia e responsabilidade para intervir no seu campo de intervenção, colaborando na definição das orientações curriculares, analisando e questionando a forma de as organizar, gerindo o currículo e tomando decisões sobre o ensino. A assunção pelo docente do seu papel enquanto gestor do currículo articula-se, assim, com uma nova conceção de profissionalidade docente, que exige uma visão própria e consciente sobre o ensino, uma prática partilhada pela comunidade de pares que 
conduza á produção de um saber próprio e a especialização na análise dos diferentes modos de aprender e as formas de fazer aprender mais adequadas (ROLDÃO, 2001).

\section{Contribuições da formação para o desenvolvimento profissional dos professores em período probatório}

Nas reflexões, os professores mentores (PM) referem ainda a perceção que tiveram sobre a contribuição do processo para o desenvolvimento profissional dos professores em período probatório (PPP), como o Quadro seguinte mostra.

Quadro 2 - Perceção dos PM sobre o contributo para o desenvolvimento dos PPP.

\begin{tabular}{|c|c|c|c|}
\hline Categorias & Subcategorias & $\begin{array}{l}\mathrm{T} \\
\mathrm{SC}\end{array}$ & $\begin{array}{l}\text { T } \\
\text { Cat }\end{array}$ \\
\hline \multirow{6}{*}{$\begin{array}{l}\text { Dimensão con- } \\
\text { ceptual }\end{array}$} & Reflexão e análise crítica sobre a ação & 38 & \multirow{6}{*}{72} \\
\hline & Apoio à tomada de decisão & 5 & \\
\hline & Diversificação de estratégias de ensino & 6 & \\
\hline & Apoio à planificação & 7 & \\
\hline & Capacidade critica & 8 & \\
\hline & Capacidade de autoavaliação & 8 & \\
\hline \multirow{7}{*}{$\begin{array}{l}\text { Dimensão opera- } \\
\text { tiva }\end{array}$} & Melhoria da capacidade de gestão do tempo & 2 & \multirow{7}{*}{45} \\
\hline & Melhoria das formas de planejamento & 5 & \\
\hline & $\begin{array}{l}\text { Atenção ao desenvolvimento nos alunos de compe- } \\
\text { tências antes negligenciadas }\end{array}$ & 7 & \\
\hline & Otimização do recurso às TIC & 2 & \\
\hline & Elaboração dos PIT & 18 & \\
\hline & Melhoria da intervenção direta com os alunos & 9 & \\
\hline & Melhoria de desempenho do professor & 2 & \\
\hline
\end{tabular}

Fonte: As autoras (2012).

Como o quadro mostra, os professores mentores, nesta dimensão, incidem mais sobre os contributos de natureza conceptual do que sobre os contributos de natureza operativa. Nos primeiros, salienta-se a reflexão e análise critica sobre a ação, referida em 38 reflexões, aspeto que já tinham assinalado como contribuição para o seu próprio desenvolvimento profissional. Na sua reflexão final, um dos professores mentores relata:

"O aspeto mais relevante nesta aprendizagem mútua (PPP e PM), foi a reflexão sobre o que é ensinar, como se pode motivar os alunos e como se pode contribuir para a melhoria de todo o nosso processo de ensino/aprendizagem. Obrigou-nos a parar para refletir porque para darmos indicações temos que olhar reflexivamente e de forma crítica para o nosso próprio processo de ensinar" (M8 Lx). 
Estando o conceito de reflexividade (SCHÖN, 1987; ROLDÃO, 2001) muito erodido pelo uso constante no discurso dos professores, todavia os testemunhos descrevem com bastante rigor os modos como tal reflexão crítica se operacionalizou, o que indicia uma mais-valia da formação neste aspeto.

Na dimensão operativa, a elaboração dos Planos Individuais de Trabalho é salientada em 18 reflexões. A elaboração deste plano deu origem a algum mal-estar inicial por parte de professores em período probatório que já tinham uma larga experiência de docência como professores contratados e que consideravam não existirem aspetos a melhorar no seu desempenho. Os professores mentores, porém, souberam ultrapassar esta situação de forma criativa e colaborativa, como narra uma das mentoras:

A reflexão acerca da construção do PIT, com base num diagnóstico do desempenho profissional e o guião orientador foram fundamentais para o "arranque" do processo. No meu caso específico, não foi tarefa fácil, uma vez que a PPP que acompanhei, como já referi, possuía bastante experiência de ensino e considerava não apresentar dificuldades de maior, mostrando alguma resistência à elaboração do PIT, nos moldes sugeridos na formação. A situação foi desbloqueada através da análise conjunta do desempenho profissional de ambas e do diagnóstico do meu próprio desempenho. Concluímos então que algumas das dificuldades eram comuns e que havia aspetos em que a própria PPP se sentia mais à vontade do que eu e vice-versa. A partir daqui foi possivel estabelecer um plano de trabalho que sofreu posteriormente algumas alterações, em função de situações concretas que foram surgindo. (M3 FA).

Esse excerto aponta, de forma clara, para uma noção de supervisão colaborativa e interpares que se distancia da perspetiva vertical e assimétrica que é carateristica da formação inicial de professores (ALARCÃO; ROLDÃO, 2008). Pelo menos em relação a alguns mentores, parece possivel afirmar que a forma como se equacionou o seu papel enquanto formandos e que explicitámos em artigo anterior influenciou o modo como eles próprios abordaram os professores em período probatório no processo de supervisão. Esta abordagem dos professores em período probatório como intervenientes diretos, responsáveis e colaborantes na supervisão criou formas de envolvimento paritário que facilitam o diálogo e a consciencialização das ações desenvolvidas no âmbito da prática pedagógica, contribuindo para a construção coletiva do conhecimento profissional a partir do interior das situações educativas (ESTRELA, 2002). Com efeito, a supervisão no contexto da escola e realizada por pares (ainda que com um estatuto diferente ao serem nomeados como mentores), exige, para ser eficaz, que se atribua ao professor supervisionado o papel de agente corresponsável pelo processo supervisivo. Essa atri-

3 Vd Leite, T. - 0 programa de formação dos mentores: conceção e planejamento - artigo inserido neste dossiê temático 
buição de um papel ativo e deliberativo ao professor supervisionado favorece o questionamento sobre a forma como ele pensa e desenvolve a profissão e cria as condições para a continuidade dos processos reflexivos sobre o ensino, após o final da supervisão.

A elaboração do PIT parece também ter ajudado a ultrapassar outra das dificuldades inicialmente salientadas por professores mentores e professores em período probatório e que dizia respeito à não coincidência entre o grupo de docência do primeiro e o do segundo (por exemplo, o PM lecionava português ou inglês e o PPP lecionava castelhano). 0 excerto seguinte ilustra esta questão:

Foi interessantíssimo fazer o chamado "diagnóstico da situação" que nos levou ao Plano Individual de Trabalho (PIT) porque, foi a partir daqui que eu percebi que não era uma prioridade, neste trabalho de Professora Mentora, eu dominar a língua de "nuestros hermanos", mas o que se pretendia era uma reflexão conjunta sobre potencialidades, necessidades, dificuldades detetadas, estratégias adotadas e objetivos fixados por ambas, no sentido de promovermos o desenvolvimento das potencialidades e das aprendizagens, responder às necessidades e ultrapassar as dificuldades detetadas, quer nas turmas que lecionei, quer nas turmas da professora em periodo probatório (M2 AV).4

A referência a esta superação atravessa todos os resultados avaliativos que se obtiveram, constituindo uma das vertentes mais visiveis da mudança vivenciada face a uma fase inicial de grande resistência e contestação por parte dos atores envolvidos.

Apesar de os contributos para a melhoria do desempenho docente serem referidos de forma mais conceptual do que operativa, é interessante ter em conta o modo como alguns supervisores relacionam o processo de supervisão com a melhoria da prática do professor em período probatório, como se pode ver nos excertos seguintes:

"Da sessão de pré-observação, passando pela observação, análise dos dados recolhidos, sessão de pós-observação, conseguimos estabelecer metas de desenvolvimento profissional como, por exemplo, melhorar a gestão do tempo, empenhar-se em que os alunos na aula de L.E. não se exprimam em L.M., a não ser em casos pontuais, diversificar estratégias, por exemplo no que concerne à leitura, sugerir a realização de trabalho de grupo e a utilização das TIC que se revelaram bastante positivas em termos de dinâmica da aula e da aquisição de conhecimentos sobre a cultura espanhola" (M2 EV).

4 Vd. Reis, P, Gonçalves, T. e Mesquita, L, Análise dos registros escritos no âmbito de um processo supervisivo; e ainda Campos, J. e Gonçalves, T. A avaliação do período probatório de professores em Portugal: perspetivas de professores mentores e gestores - artigos inseridos neste dossiê temático 
"Para isso, partilhámos opiniões e práticas, quer antes da observação da aula, quer após, nos vários momentos de autorreflexão crítica que se seguiram e procurámos conjuntamente escolher outras formas de organizar e planear as aulas para que a aprendizagem dos alunos, fosse eficaz e melhorasse a relação pedagógica entre as várias partes envolvidas no processo. As aulas foram planeadas de modo a que as tarefas se centrassem mais nos alunos, permitindo um maior envolvimento destes, e consequentemente um maior desenvolvimento da autonomia destes. A avaliação dos alunos foi também mais centrada em trabalhos de carácter prático e trabalhos projeto e não em testes escritos como até aí. Estas estratégias resultaram, uma vez que, se notou a diferença do envolvimento dos alunos, das primeiras aulas para as restantes. Deixaram de ser simples espectadores para começarem a ser atores. [...]" (M9 EV).

Estes excertos das reflexões dos mentores mostram a importância da focagem da supervisão nas situações de ensino, tendo em conta o planejamento curricular e a análise do processo e dos resultados. Como referimos antes, no quadro da docência entendida como profissão, o professor tem um papel decisivo da gestão do currículo e uma das dimensões desse papel reside na conceção estratégica da ação pedagógica. Nessa dimensão, interatuam conhecimentos, valores e crenças do professor, alguns dos quais conscientes e explicitados, outros apenas implícitos e tácitos. 0 desenvolvimento profissional dos professores passa necessariamente pela análise, reajustamento e redefinição desses conhecimentos, valores e crenças, tendo em conta não apenas o que se ensina e como se ensina, mas também porque e para quê se ensina alguma coisa (DAY, 2001). Como reconhece Stenhouse (1975, apud STENHOUSE, 1998) não pode haver desenvolvimento curricular sem desenvolvimento profissional docente.

A focagem da supervisão nas situações de ensino permitiu a criação de espaços de diálogo para a análise do real e procura conjunta de soluções alternativas para organização dos percursos de aprendizagem dos alunos, criando uma rede de entreajuda e apoio que facilitou, como os excertos anteriores mostram, a mudança na prática pedagógica dos professores em período probatório.

\section{Contribuições da formação para o desenvolvimento organizacional das escolas}

0 terceiro campo de análise incide sobre a contribuição do processo para o desenvolvimento organizacional da escola e o quadro seguinte mostra os resultados obtidos. 
Quadro 3 - Contribuição para o desenvolvimento organizacional da escola.

\begin{tabular}{|l|l|l|l|}
\hline \multirow{5}{*}{ Categorias } & Subcategorias & $\begin{array}{l}\text { T } \\
\text { SC }\end{array}$ & $\begin{array}{l}\text { T } \\
\text { Cat }\end{array}$ \\
\hline \multirow{5}{*}{ Aspetos positivos } & $\begin{array}{l}\text { Inserção/acompanhamento do PP no/pelo Depar- } \\
\text { tamento Curricular }\end{array}$ & 11 & \\
\cline { 2 - 3 } & $\begin{array}{l}\text { Criação de uma dinâmica colaborativa entre } \\
\text { professores }\end{array}$ & 14 & \\
\cline { 2 - 3 } & Maior inserção do PPP na escola & 3 & \multirow{2}{*}{32} \\
\cline { 2 - 4 } Limitações & $\begin{array}{l}\text { Apoio de outros professores da escola, quando } \\
\text { necessário }\end{array}$ & 3 & 1 \\
\cline { 2 - 4 } & Alargamento à comunidade & 3 & \multirow{2}{*}{ Fraca visibilidade do PP no Agrupamento } \\
\hline & $\begin{array}{l}\text { Escasso reconhecimento pelo Agrupamento do } \\
\text { trabalho desenvolvido }\end{array}$ & 2 & \\
\hline
\end{tabular}

Fonte: As autoras (2012).

Como afirmámos antes, as referências a este assunto são em menor número e menos diversificadas que aquelas que surgem nos outros campos analisados. 0 maior número de referências incide no trabalho colaborativo entre o professor mentor e o professor em período probatório, entre os professores mentores da mesma escola ou concelho e entre os professores em período probatório da mesma ou de várias escolas. Este tipo de situação corresponde também á menor incidência do programa nestas dimensões. No entanto, algumas reflexões salientam o acompanhamento por parte do Departamento Curricular ou de outros professores da escola, o que parece ter ocorrido sobretudo quando o PM não era do mesmo grupo de docência do PPP como o excerto seguinte mostra.

"A nível da direção da escola e do grupo disciplinar, a PPP teve todo o apoio e tudo foi feito para que se sentisse integrada. 0 único aspeto menos positivo foi o facto de não lhe poder ser atribuída a redução horária, nem uma direção de turma, como previsto, por questões organizacionais" (M9 FA).

0 envolvimento dos PM e dos PPP na formação parece ainda ter criado, em algumas escolas, processos de colaboração entre docentes, como afirma esta mentora:

"Inesperadamente, esta Oficina de Formação, pelo carácter formativo que teve, desencadeou a nivel do estabelecimento de ensino um trabalho colaborativo entre os docentes do ensino especial" (M9 LX). 
De salientar que o alargamento à comunidade é referido apenas numa reflexão. Por outro lado, alguns mentores consideram que o período probatório teve fraca visibilidade ou reconhecimento por parte do Agrupamento de Escolas.

Tendo em conta as afirmações e constatações dos poucos mentores que se reportam a este aspeto, e o predomínio da sua ausência, parece possível concluir que o programa de apoio ao período probatório teve pouca visibilidade e impacto no desenvolvimento organizacional dos Agrupamentos. Foi também, de facto, uma dimensão com menor investimento por parte da equipa que teve dificuldade em atingir os diretores, e, através deles, as escolas e agrupamentos, na medida em que este processo funcionou na prática como dissociado da vida normal da organização. ${ }^{5}$

\section{Qualidade e utilidade globais do processo formativo}

No quadro seguinte apresentam-se os resultados relativos à perceção dos mentores sobre a qualidade e utilidade do processo formativo. Uma primeira constatação de carácter geral é que os mentores valorizam a formação em que participaram, mas também são críticos em relação a alguns aspetos.

Quadro 4 - Qualidade e utilidade da formação em supervisão.

\begin{tabular}{|l|l|l|l|}
\hline \multirow{4}{*}{ Categorias } & Subcategorias & T & T \\
Cat \\
\hline \multirow{5}{*}{ Aspetos positivos } & Partilha de experiências e dificuldades & 25 & \\
\cline { 2 - 3 } & Debate de ideias & 13 \\
\cline { 2 - 3 } & Identificação de problemas e procura de soluções & 5 \\
\cline { 2 - 4 } & Esclarecimento de dúvidas & 7 \\
\cline { 2 - 4 } & Disponibilidade dos formadores & 15 \\
\cline { 2 - 4 } & Suporte efetivo à supervisão & 12 \\
\cline { 2 - 4 } & Adequação e clareza dos temas abordados & 14 \\
\cline { 2 - 4 } & Adequação dos documentos disponibilizados & 32 \\
\cline { 2 - 4 } & Elaboração e apresentação dos posters & 7 \\
\cline { 2 - 4 } & Recurso à plataforma e correio eletrónico & 3 \\
\cline { 2 - 4 } & Recurso ao trabalho de grupo & 3 \\
\cline { 2 - 4 } & Respeito pelas práticas de cada escola & 3 \\
\cline { 2 - 4 } & Focagem na ação de ensinar & 6 \\
\cline { 2 - 4 } & Oualidade dos formadores & 6 \\
\hline
\end{tabular}

(Continuação)

5 Realizou-se uma reunião nacional só para Diretores, em que apenas cerca de um terço compareceu, mostrando-se sobretudo inquietos com os procedimentos administrativos associados à avaliação dos PPP. Foram também convidados a estar presentes nos 2 Seminários nacionais que a equipa promoveu na Universidade de Aveiro, para além de solicitados a apreciar o processo mediante um questionário específico. 
(Continuação)

\begin{tabular}{|c|c|c|c|}
\hline \multirow{11}{*}{ Limitações } & Ausência de formação antes do início do processo & 21 & \\
\hline & $\begin{array}{l}\text { Ausência de definição do perfil desejável do PPP } \\
\text { como referente para avaliacão }\end{array}$ & 7 & \\
\hline & Ausência de formação direta ao PPP & 3 & \\
\hline & Ausência de documentação prévia à formação & 6 & \\
\hline & Escassa rentabilização da plataforma & 4 & \\
\hline & Necessidade de relatos de supervisão & 1 & \\
\hline & $\begin{array}{l}\text { Necessidade de maior análise crítica dos instru- } \\
\text { mentos de supervisão }\end{array}$ & 1 & \\
\hline & Individualização no feedback aos trabalhos & 1 & \\
\hline & Falta de tempo & 7 & \\
\hline & Mais espaços de reflexão & 1 & \\
\hline & Ausência de rentabilização para o sistema & 5 & 7 \\
\hline
\end{tabular}

Fonte: As autoras (2012).

Nos aspetos positivos, o mais referido é o que se relaciona com a adequação dos documentos disponibilizados, referido em 32 reflexões. Esses documentos abrangem quer os materiais fornecidos durante as aulas, quer as brochuras publicadas especificamente como apoio ao programa de acompanhamento do período probatório. Uma das mentoras afirma:

"Passo a destacar alguns aspetos que considero dignos de menção porque, de uma forma ou de outra, fizeram parte do meu crescimento enquanto supervisora. Assim, os documentos "Dimensões da Ação de Ensinar" e "Conceito de Supervisão e de Desenvolvimento Profissional" permitiram a reflexão e o debate sobre as dimensões: conceção, operacionalização, avaliação e reorientação, tão importantes num percurso docente e, no que diz respeito ao conceito de supervisão: finalidade, focagem, estratégias e feedback." (M2 EV).

Os mentores destacam também a orientação e organização das sessões, focando a possibilidade de partilhar experiências, dificuldades e ideias, a disponibilidade dos formadores e a adequação da abordagem dos conteúdos, constituindo as sessões um suporte efetivo ao processo desenvolvido no terreno. Mais uma vez se ilustra, neste campo, a adesão ao formato de oferta formativa que se desenvolveu, alicerçado num permanente vaivém entre questões emergentes da prática e a sua teorização e análise, o que parece ter sido considerado como eficaz.

Nos aspetos negativos, salienta-se a simultaneidade da formação com o desenvolvimento do processo de supervisão no terreno, a qual é percecionada como negativa por 21 mentores. 
"Para futuras formações com os mesmos objetivos, parece-me oportuno referir aquilo que os formadores, por certo, também sabem e sentem, isto é, que a formação do PM se deve fazer com a distância temporal necessária à apropriação dos conhecimentos necessários para o desempenho das suas funções. Assim, os materiais também serão facultados com maior antecedência e $\mathrm{o} P \mathrm{PM}$ poderá pôr em prática, individualmente ou em grupo, alguns trabalhos a realizar posteriormente pelo PPP, pois pela experiência se estimula e se conduz." (M2 EV). "Para futuras formações com os mesmos objetivos, creio ser importante que as sessões se realizem mais atempadamente a fim de permitir que o professor mentor, sobretudo aquele com menos experiência nesta matéria, possa encetar a sua ação de forma mais orientada e organizada (M6 BR).

Esta preferência dos mentores pela formação anterior ao início do desempenho supervisivo corresponde ao modelo tradicional de relação teoria-prática que consiste em ver a prática como aplicação da teoria e que foi, durante largo tempo, característico da formação inicial de professores. Este tipo de abordagem cria uma segurança aparente nos intervenientes, que se consideram munidos dos conhecimentos necessários ao desenvolvimento das ações futuras, mas não favorece a leitura e questionamento do real à luz de um quadro de referências sólido e coerente, nem a conceção e planejamento de soluções inovadoras para resolver as situações concretas. Neste sentido, foi opção da equipa de formação incentivar processos que permitissem a teorização da ação, através de estratégias que proporcionassem o vaivém teoria-prática, enquadradas em modelos de formação de professores centrados na análise ${ }^{6}$.

Por outro lado, a ausência de definição de um perfil desejável para o PPP constituiu, para 7 mentores, um fator negativo, uma vez que dificultou a criação de critérios e indicadores de avaliação. Um dos mentores afirma:

"Outra das vertentes formativas, no âmbito da avaliação, que na minha opinião carece de maior investimento no futuro diz respeito à definição e criação de critérios, indicadores e níveis de ação docente que permitam a qualquer supervisor enquadrar e categorizar desempenhos com a maior objetividade possível. Fica ainda a expectativa e a intenção de ver futuramente estas vertentes serem objeto de reflexão e de construção também em contexto escolar." (M3 LX).

Estas afirmações sugerem que a focagem do desenvolvimento profissional nas várias dimensões do ato de ensinar, preocupação dominante durante todo o processo

6 Ver Leite, T. 0 programa de formação de mentores: concepção e planejamento -artigo inserido neste dossiê temático 
formativo, não foi suficiente para operacionalizar critérios e indicadores de avaliação, necessitando os mentores de uma definição mais explícita de padrões de desempenho.

Com efeito, a criação de um quadro de referência claro para a prática profissional é fundamental para a avaliação e autoavaliação dos docentes. Como afirma Danielson (2010 p. 2), "porque ensinar é uma atividade complexa, é útil possuir um mapa do território, estruturado à volta de um entendimento partilhado do que é ensinar".

Por outro lado, é necessário ter em conta que avaliação docente e supervisão nem sempre têm sido encaradas como processos integrados. Nolan e Hoover (2005, apud MOREIRA, 2009) apresentam, de forma muito clara, as diferenças entre supervisão e avaliação docente, considerando a finalidade, o âmbito e a relação entre os intervenientes. No entanto, é possivel integrar estas duas funções se a avaliação for entendida numa perspetiva formativa e como meio de promover o desenvolvimento profissional.

Para tal, é necessário associar o professor avaliado ao processo de avaliação. A eficácia da supervisão no processo de avaliação de professores depende do modo como é encarado o papel do professor avaliado, uma vez que "as práticas de supervisão devem ser, em grande parte, reguladas pelo professor" (DANIELSON, 2010 p. 177). Também Marchão $(2011$, p. 4) salienta que "num processo de supervisão-avaliação é necessária a corresponsabilização no processo avaliativo e um diálogo permanente numa perspetiva auto e héterorreflexiva que permita a evolução do professor avaliado, a melhoria e mudança de práticas [...]"

De salientar ainda que 5 professores mentores preveem, com desagrado, a ausência de rentabilização desta ação para o sistema, manifestando ter adquirido ou desenvolvido uma visão global da política de formação e da necessidade de rentabilizar o conhecimento e capacitação adquiridos, em lugar de os desperdiçar. 0 excerto seguinte pode servir de exemplo deste tipo de afirmações:

Este é um processo iniciado. Considero-o como um primeiro passo, num caminho que deve ser prosseguido. Não sei como será o próximo ano. Com todas as modificações do processo avaliativo que estão em cima da mesa, imagino que muitos dos atuais protagonistas, deixarão de o ser no próximo ano. E tudo voltará, em muitos casos à estaca zero. E se assim for, muita coisa se deitará fora. E é pena [...] (M9 BR).

Em jeito de sintese, este conjunto de reflexões dos PM, sujeitos em formação e, também, sujeitos da formação, permitindo visibilizar que um processo complexo e dificultado por razões circunstanciais adversas, conseguiu sustentar um grau apreciável de impacto no desenvolvimento profissional dos intervenientes, nomeadamente mediante a estratégia formativa desenvolvida que se mostrou eficaz. 
Nessa estratégia, sublinha-se (1) a teorização constante da ação no terreno e seu aprofundamento, (2) a importância do fornecimento, uso e análise de materiais de apoio, e a devolução de feedback.

\section{Referências}

ALARCÃO, I. Escola reflexiva e supervisão: uma escola em desenvolvimento e aprendizagem. Porto: Porto Ed., 2000.

ALARCÃO, I.; LEITÃO, A.; ROLDÃO, M. C. Prática pedagógica supervisionada e feedback formativo co-construtivo. Revista brasileira de formação de professores, Goiânia, v. 1, n. 3, p. 2-29, dez., 2009. Disponivel em: < http:// www.facec.edu.br/seer/index.php/formacaodeprofessores/article/view/109/157>. Acesso em: 30 out. 2012.

ALARCÃO, I.; ROLDÃO, M. C. Supervisão: um contexto de desenvolvimento profissional dos professores. Mangualde: PEDAG0, 2008.

ALARCÃO, I.; TAVARES, J. Supervisõo da prótica pedagógica: uma perspectiva de desenvolvimento e aprendizagem. 2. ed. rev. e atual. jan. 2003. Coimbra: Almedina, 2010. (Coleção Ciências da Educação e Pedagogia.).

COCHRAN-SMITH, M.; LYTLE, S. Relationship of knowledge and practice: teacher learning in communities. Review of Research in Education, Thousand Oaks, CA, v. 24, n. 1, p. 249-305, jan. 1999.

DANIELSON, C. Melhorar a prática profissional: um quadro de referência para a docência. Lisboa: Ministério da Educação, 2010.

DAY, C. Desenvolvimento profissional de professores: os desafios da aprendizagem permanente. Porto: Porto Ed., 2001.

ESTEVES, M. Análise de conteúdo. In: LIMA, J. A.; PACHECO, J. A. Fazer investigação: contributos para a elaboração de dissertações e teses. Porto: Porto Editora, 2005.

ESTRELA, M. T. Modelos de formação de professores e seus pressupostos conceptuais. Revista de Educação, Lisboa, v. 11, n. 1, p. 17-20, 2002.

LEITE, T. Planeamento e conceção da ação de ensinar. Aveiro: Universidade de Aveiro. Aveiro: Universidade de Aveiro, 2010. (Coleção Situações de Formação n. 2). 
MARCHÃO, A. J. Desenvolvimento profissional dos educadores e dos professores: é possivel conciliar a supervisão e a avaliação de desempenho?. Profforma: Revista on line do Centro de formação de professores do Nordeste Alentejano, Portugal, n. 3, jun. 2011. Disponivel em: < http://www.cefopna.edu.pt/revista/ revista_03/es_06_03_AM.htm>. Acesso em: 30 out. 2012.

MOREIRA, M. A. A avaliação do (des)empenho docente: perspetivas da supervisão pedagógica. In: VIEIRA, F. et al. (Org.). Pedagogia para a autonomia: reconstruir a esperança na educação. Braga: CIED, 2009. (ENCONTRO DO GRUPO DE TRABALHO-PEDAGOGIA PARA A AUTONOMIA, 4., 2009, Braga. Anais... Braga: CIED, 2009, p. 241-258.).

PUTNAM, R. T.; BORKO, H. What do news views of knowledge and thinking have to say about research on teacher learning?. Educational Research, Berkeley, v. 29, n. 1, p. 4-15, jan. 2000.

ROLDÃO, M. C. A mudança anunciada da escola ou um paradigma de escola em ruptura?. In: ALARCÃO, I. (Org.). Escola reflexiva e nova racionalidade. São Paulo: ArtMed, 2001. p. 115-134.

Construção de planos individuais de trabalho e desenvolvimento profissional. Aveiro: Universidade de Aveiro, 2010a. (Colecção Situações de Formação, n. 1).

. Ensinar e aprender: o saber e o agir distintivos do profissional docente. In: ENS, R. T.; BEHRENS, M. A. (Org.). Formação do professor. profissionalidade, pesquisa e cultura escolar. Curitiba: Ed. Champagnat, 2010b. p. 25-42.

Estratégias de Ensino: o saber e o agir do professor. Vila Nova de Gaia: Fundação Manuel Leão, 2009.

. Função docente: natureza e construção do conhecimento profissional. Revisto Brasileira de Educação, Rio de Janeiro, v. 12, n. 34, p. 94-103, jan./abr. 2007.

Profissionalidade docente em análise: especificidades dos ensinos superior e não superior. Revista Nuances, São Paulo, ano 11, n. 13, p. 108-126, jan./dez. 2005.

Um currículo de currículos. Chamusca: Edições Cosmos, 2011.

SCHON, D. A. Educating the reflective practitioner. San Francisco: Jossey-Bass Publishers, 1987. 
. The reflective practioner. how professionals think in action. New York:

Basic Books, 1983.

STENHOUSE, L. Investigación y desarrollo del curriculum. Madrid: Ediciones Morata, 1998.

STOLL, L et al. Professional learning communities: a review of literature. Journa/ of educational change, v. 7, p. 221-258. jul. 2006.

Recebido em: 12/04/2012

Aceito para publicação em: 18/07/2012 